\title{
Separation of thiophene from aliphatic hydrocarbons using tetrahexylammonium-based deep eutectic solvents as extracting agents
}

\author{
Citation for published version (APA): \\ Warrag, S. E. E., Rodriguez, N. R., Nashef, I. M., Van Sint Annaland, M., Siepmann, J. I., Kroon, M. C., \& \\ Peters, C. J. (2017). Separation of thiophene from aliphatic hydrocarbons using tetrahexylammonium-based \\ deep eutectic solvents as extracting agents. Journal of Chemical and Engineering Data, 62(9), 2911-2919. \\ https://doi.org/10.1021/acs.jced.7b00168
}

\section{Document license: \\ TAVERNE}

DOI:

10.1021/acs.jced.7b00168

Document status and date:

Published: 14/09/2017

\section{Document Version:}

Publisher's PDF, also known as Version of Record (includes final page, issue and volume numbers)

\section{Please check the document version of this publication:}

- A submitted manuscript is the version of the article upon submission and before peer-review. There can be important differences between the submitted version and the official published version of record. People interested in the research are advised to contact the author for the final version of the publication, or visit the DOI to the publisher's website.

- The final author version and the galley proof are versions of the publication after peer review.

- The final published version features the final layout of the paper including the volume, issue and page numbers.

Link to publication

\footnotetext{
General rights

- You may freely distribute the URL identifying the publication in the public portal. follow below link for the End User Agreement:

www.tue.nl/taverne

\section{Take down policy}

If you believe that this document breaches copyright please contact us at:

openaccess@tue.nl

providing details and we will investigate your claim.
}

Copyright and moral rights for the publications made accessible in the public portal are retained by the authors and/or other copyright owners and it is a condition of accessing publications that users recognise and abide by the legal requirements associated with these rights.

- Users may download and print one copy of any publication from the public portal for the purpose of private study or research.

- You may not further distribute the material or use it for any profit-making activity or commercial gain

If the publication is distributed under the terms of Article $25 \mathrm{fa}$ of the Dutch Copyright Act, indicated by the "Taverne" license above, please 


\title{
Separation of Thiophene from Aliphatic Hydrocarbons Using Tetrahexylammonium-Based Deep Eutectic Solvents as Extracting Agents
}

\author{
Samah E. E. Warrag, ${ }^{\dagger \neq}$ Nerea R. Rodriguez, ${ }^{\ddagger}$ Inas M. Nashef, ${ }^{\S}$ Martin van Sint Annaland,
} J. Ilja Siepmann, ${ }^{\| \odot ~ M a a i k e ~ C . ~ K r o o n, ~}{ }^{*},{ }^{\dagger} \odot$ and Cor J. Peters ${ }^{\dagger}$

${ }^{\dagger}$ Khalifa University of Science and Technology, Petroleum Institute, Chemical Engineering Department, P.O. Box 2533, Abu Dhabi, United Arab Emirates

${ }^{\ddagger}$ Eindhoven University of Technology, Department of Chemical Engineering and Chemistry, Process Intensification Group, P.O. Box 513, 5600 MB Eindhoven, The Netherlands

${ }^{\S}$ Khalifa University of Science and Technology, Masdar Institute, Department of Chemical and Environmental Engineering, P.O. Box 54224, Abu Dhabi, United Arab Emirates

"University of Minnesota, Department of Chemistry and Chemical Theory Center, 207 Pleasant Street SE, Minneapolis, Minnesota 55455, United States

\section{Supporting Information}

\begin{abstract}
Catalytic hydrodesulfurization is the common process that is used in the industry to achieve low sulfur concentrations in oil fuels. However, it is usually conducted at relatively high pressure and temperature resulting in an expensive and energy-consuming process. Aiming to reduce the energy requirements of this separation, liquid-liquid extraction is considered. In this work, two deep eutectic solvents (DESs) were evaluated for their extraction properties of sulfur derivatives from two aliphatic hydrocarbons via liquid-liquid extraction. The mixtures thiophene $/ n$-hexane and thiophene $/ n$-octane were selected as oil models. The selected DESs were: (i) tetrahexylammonium bromide/
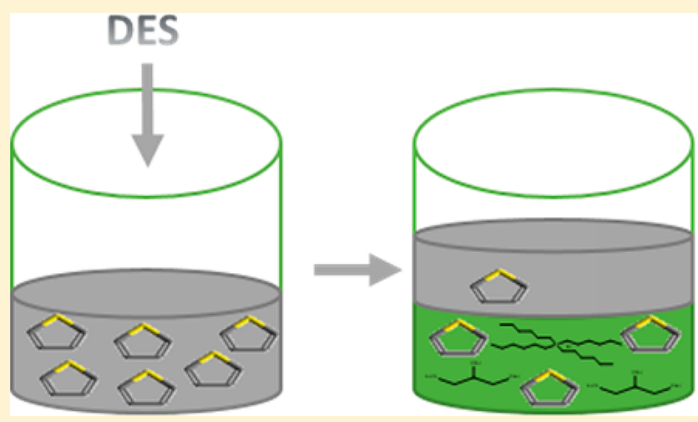

Aliphatic Phase

DES

Phase ethylene glycol with molar ratio = 1:2 (DES 1) and (ii) tetrahexylammonium bromide/glycerol with molar ratio = 1:2 (DES 2). To confirm the suitability of the DESs for the system \{aliphatic + thiophene + DES \}, the binary solubility of thiophene/DES and aliphatic/DES was measured at $T / K=298$ and atmospheric pressure. Then, the liquid-liquid equilibrium (LLE) data of the ternary systems $\{n$-hexane + thiophene + DES 1$\},\{n$-hexane + thiophene + DES 2$\},\{n$-octane + thiophene + DES 1$\}$, and $\{n$ octane + thiophene + DES 2$\}$ were determined at $T / K=298$ and atmospheric pressure. The experimental LLE data were correlated using the nonrandom two-liquid thermodynamic model. Also, the solute distribution ratios and the selectivities were calculated from the experimental LLE data and compared to the relevant literature. Finally, the DESs were successfully regenerated by means of vacuum evaporation. It was found that the DESs are potential solvents for extractive desulfurization processes.
\end{abstract}

\section{INTRODUCTION}

Sulfur oxides $\left(\mathrm{SO}_{x}\right)$ are major air pollutants and have significant health impacts. $\mathrm{SO}_{x}$ emissions are a precursor to acid rain and atmospheric particulates. The main source of $\mathrm{SO}_{x}$ emissions is the combustion of fossil fuels that contain relatively high concentrations of sulfur and sulfur derivatives. Therefore, governmental regulations such as EPA's Acid Rain Program established under title IV of the 1990 Clean Air Act (CAA) amendments regarding the sulfur content of fuels continue to be enacted worldwide. ${ }^{1}$ Moreover, sulfur and its derivatives are harmful to oil and gas processing units as they are causes of catalyst poisoning. ${ }^{2}$ Sulfur exists in oil and gas as pure sulfur, hydrogen sulfide, sulfides $(\mathrm{R}-\mathrm{S}-\mathrm{R})$, thiols, and thiophenes. ${ }^{3}$
Hydrodesulfurization (HDS) is the established approach for the removal of sulfur and its derivatives in the industry. HDS is a catalytic process that removes sulfurs via the conversion into hydrogen sulfide $\left(\mathrm{H}_{2} \mathrm{~S}\right){ }^{4,5}$ However, the process is typically conducted at temperatures of $573.2-673.2 \mathrm{~K}$ and pressures of 3.5-7.0 MPa that results in high operational cost. ${ }^{6}$ In the past few decades, scientists have looked at many different desulfurization approaches including oxidative desulfurization, ${ }^{7}$

Special Issue: Memorial Issue in Honor of Ken Marsh

Received: February 14, 2017

Accepted: July 17, 2017

Published: August 7, 2017 
biodesulfurization, ${ }^{8}$ adsorption, ${ }^{9}$ and extractive desulfurization. $^{10,11}$ The mentioned alternatives were successful solutions in terms of desulfurization efficiency and mild operating conditions except for adsorption. Nevertheless, the use of traditional volatile organic solvents e.g., acetonitrile, methanol, or dimethylformamide raised safety and environmental concerns due to their volatilities. Extractive desulfurization using ionic liquids (ILs) as extracting agents has emerged as a promising alternative for the organic solvents due to their nonvolatility, low flammability, thermal stability, and high solvation properties. ${ }^{12,13}$ Although many studies have proven the efficiency of ILs for desulfurization, ${ }^{14-19}$ their high synthesis cost and toxicity hindered their industrial application. In this work, the main objective is to exploit an alternative that is more energy efficient, economical, and with high desulfurization capacity.

Deep eutectic solvents (DESs) are arising as alternatives to ILs that provide similar solvation properties, low vapor pressure, low flammability, wide liquid range, and thermal stability while overcoming the high synthesis cost and toxicity of ILs. ${ }^{20}$ DESs are liquids at room temperature and consist of one or more hydrogen bond donors (HBDs) and one or more hydrogen bond acceptors (HBAs) that form, upon mixing, a low melting point mixture with significantly low vapor pressure. The DESs can be prepared from low-cost constituents that are usually found in nature. Thus, DESs are generally considered as sustainable and environmentally benign solvents. DESs became an attractive research topic and has been applied in different fields mostly inspired by IL applications such as material synthesis, electrochemistry, biochemistry, catalysis, and separations technologies and others. ${ }^{20-22}$ DESs have also been applied for desulfurization of different fuel models. Li et al. ${ }^{23}$ reported desulfurization efficiencies of $81.75 \%, 80.47 \%$, and $72 \%$ in a single stage for benzothiophene, dibenzothiophene, and thiophene, respectively, from n-octane using carboxylic acid-based DESs in a solvent-to-feed ratio of 1:0.5 (DES/oil). It was found that efficiency is insensitive to the extraction temperature, and after three extraction cycles deep desulfurization can be attained (up to 98\% extraction efficiency). Interestingly, the regeneration of the DES has been performed using methyl tert-butyl ether as back-extractant and the DES extraction property was completely recovered. Another research group $^{24}$ synthesized ammonium salts based-DESs for the extraction of benzothiophene from fuels in which the extraction efficiency could reach up to $99 \%$ after five cycles. Few other studies in the literature reported the DESs' extraction ability of thiophene compounds; ; $^{25-28}$ however, there is a lack of fundamental studies on the liquid-liquid equilibrium (LLE) of the $\{$ aliphatic + thiophene/thiophene derivative + DES $\}$ systems. To present, only one LLE study for the system $\{n$ heptane + thiophene + DES $\}$ has been reported by Hadj-Kali et al. $^{29}$ Knowledge of LLE is vital for the design and optimization of efficient deep desulfurization processes. Therefore, in this work DESs were evaluated as extracting agents for the separation of thiophene from \{aliphatic hydrocarbon + thiophene $\}$ mixtures via liquid-liquid extraction. The mixtures thiophene/ $n$-hexane and thiophene/n-octane were selected as oil models. The selected DESs were (i) tetrahexylammonium bromide/ethylene glycol with molar ratio $=1: 2($ DES 1$)$ and (ii) tetrahexylammonium bromide/glycerol with molar ratio = 1:2 (DES 2). These DESs and ratios were selected due to their potential ability for the removal of aromatics from \{aliphatic + aromatic $\}$ mixtures as previously reported in the literature. ${ }^{30}$ As described in the cited work, ${ }^{30}$ the $\pi$-electrons in the aromatic ring induce the interaction with DES leading to an efficient extraction of the aromatic compound. $\pi$-Electrons are also available in thiophene and in addition the existence of sulfur increases its reactivity; thus, the workability of these DESs was expected. To confirm the suitability of these DESs for the systems $\{$ aliphatic + thiophene $+\mathrm{DES}\}$, the binary solubility of thiophene/DES and aliphatic/DES was tested at $T / \mathrm{K}=298.2$ and atmospheric pressure. Then, LLE data of the ternary systems $\{n$-hexane + thiophene + DES 1$\},\{n$-hexane + thiophene + DES 2\}, \{n-octane + thiophene + DES 1$\}$, and \{ $n$-octane + thiophene + DES 2$\}$ were determined at $T / K=$ 298.2 and atmospheric pressure. This was done in order to study the role of the hydrogen bond donor (HBD) of the DES for the extraction of thiophene and the influence of the aliphatic hydrocarbon type/length. The experimental LLE data were correlated using the nonrandom two-liquid (NRTL) thermodynamic model. To evaluate the separation capability of the studied DESs, the solute distribution ratio and the selectivity were calculated from the experimental LLE data and compared to relevant literature data. Finally, the DESs were successfully regenerated by means of vacuum evaporation.

\section{EXPERIMENTAL PROCEDURE}

2.1. Chemicals. The source and purity (as stated by the suppliers) of all the chemicals used in this work are presented in Table 1. All the chemicals were used without further purification.

Table 1. Source, Purity and Melting Point (As Stated by the Suppliers) of the Chemicals Used in This Work

\begin{tabular}{llcc}
\multicolumn{1}{c}{ chemical } & \multicolumn{1}{c}{ source } & $\begin{array}{c}\text { purity } \\
\%)\end{array}$ & $\begin{array}{c}\text { melting } \\
\text { point }\end{array}$ \\
thiophene & Sigma-Aldrich & $\geq 99$ & \\
hexane & Sigma-Aldrich & $\geq 95$ & \\
octane & Sigma-Aldrich & $\geq 99$ & \\
$\begin{array}{l}\text { tetrahexylammonium } \\
\text { bromide }\end{array}$ & Sigma-Aldrich & $\geq 99$ & $398.2 \mathrm{~K}$ \\
glycerol & Merck KGaA & $\geq 99$ & $291.2 \mathrm{~K}$ \\
ethylene glycol & Sigma-Aldrich & $\geq 99$ & $260.2 \mathrm{~K}$ \\
ethanol & TechniSolv & $\geq 99.5$ & \\
\hline
\end{tabular}

2.2. Preparation of the DESs. The DESs used in this work were prepared according to the heating method. The heating method requires that the precisely weighted amounts of HBD and HBA are heated together at a certain temperature while stirring in a sealed flask until a clear liquid is formed. The weighing of both the HBD and the HBA was done using a balance Mettler AX205 with an uncertainty in the measurement of $\pm 0.2 \times 10^{-4} \mathrm{~g}$. The mixture was heated at $T / \mathrm{K}=333.2$ in a thermostatic bath (IKA RCT basic) with a temperature controller (IKA ETS-D5) with an uncertainty in the measurement of $T / K= \pm 0.1$. The DESs prepared were: (i) tetrahexylammonium bromide/ethylene glycol with molar ratio $=1: 2$ (DES 1) and (ii) tetrahexylammonium bromide/ glycerol with molar ratio $=1: 2$ (DES 2). The molecular structures of DES 1 and DES 2 are shown in Table 2. The structure of the DES was verified by 400 Bruker nuclear magnetic resonance (NMR) spectrometer for ${ }^{1} \mathrm{H}$ NMR (Figures S.1 and S.2). The density and viscosity of the prepared DESs can be found elsewhere. ${ }^{30}$ 
Table 2. Molecular Structures of DES 1 and DES 2

\begin{tabular}{|c|c|c|c|}
\hline DES & HBA & $\begin{array}{c}\text { Molar } \\
\text { ratio }\end{array}$ & HBD \\
\hline DES 1 & & & \\
\hline DES 2 & & & \\
\hline
\end{tabular}

The water content was measured after the DESs preparation using the Karl Fischer titration method (type Metrohm 899). It is well-known that the properties of the DESs are highly dependent on the water content. Therefore, it is of great importance to report the water content of the DESs. The obtained values are listed in Table 3.

Table 3. Water Content of the Prepared DESs

\begin{tabular}{cc} 
DES & Water content (wt \%) \\
DES 1 & 0.489 \\
DES 2 & 0.449 \\
\hline
\end{tabular}

2.3. Experimental Determination of the Binary and Ternary LLE Data. The LLE data of the binary and ternary mixtures $\{n$-hexane $+\mathrm{DES}\},\{n$-octane $+\mathrm{DES}\},\{n$-hexane + thiophene + DES $\}$, and $\{n$-octane + thiophene + DES $\}$ were experimentally determined using the equilibrium cell method. On the contrary, the LLE data of the binary mixtures \{thiophene + DES 1$\}$ and \{thiophene + DES 2\} were experimentally determined using the cloud point method. The reason for using the cloud point method instead of the equilibrium cell method is the high/full solubility of thiophene in the selected DESs. This means that the obtained phase would be too small for a proper sampling. It is important to remark that the cloud point method is a qualitative method, highly dependent on the experimentalist observation; therefore, the obtained results should be considered with caution.

For the equilibrium cell method, different amounts of DES, thiophene, and/or the aliphatic compound were added to 20 $\mathrm{mL}$ headspace vials. The quantity of added components was measured with a balance Mettler AX205 with an uncertainty in the measurement of $\pm 0.2 \times 10^{-4} \mathrm{~g}$. The vials were stirred for 2 $\mathrm{h}$ at $500 \mathrm{rpm}$ in a temperature controlled incubated shaker (IKA KS 4000) i-control with temperature stability of $T / \mathrm{K}= \pm$ $0.1 \mathrm{kept}$ at $298.2 \mathrm{~K}$. Then, the mixtures were left to settle overnight in a heating block to reach thermodynamic equilibrium. The heating block was kept at $298.2 \mathrm{~K}$ on a hot plate (IKA RCT basic) with a temperature controller (IKA ETS-D5). Thereafter, both phases were sampled using needled syringes.

The composition of both phases was determined via gas chromatography (Varian 430 equipped with flame ionization detector). The column and the GC method used for the analysis is described in Table 4. In all the measurements ethanol was used as dilution agent. Since the DES cannot be quantified via gas chromatography, its concentration was determined via mass balance calculation. The GC method was validated with samples of known composition and the
Table 4. Column Type and Analysis Conditions of the GC Method Used for the Determination of the Compositions

$\begin{array}{ll}\text { column } & \text { Varian CP-SIL 5CB }(25 \mathrm{~m} \times 0.25 \mathrm{~mm} \times 1.25 \mu \mathrm{m}) \\ \text { injector temperature } & 548.2 \mathrm{~K} \\ \text { oven temperature profile } & 313.2-353.2 \text { at } 12.5 \mathrm{~K} / \mathrm{min} \\ \text { detector temperature } & 473.2 \mathrm{~K} \\ \text { carrier gas } & \text { helium } \\ \text { flow rate } & 3 \mathrm{~mL} / \mathrm{min} \\ \text { split ratio } & 200 \\ \text { injection volume } & 1 \mu \mathrm{L}\end{array}$

obtained root-mean-square deviation (RMSD) was equal to 0.05 for all the samples. During the experiments, all samples were measured five times and the statistical uncertainty in the measurement was found to be less than 0.005 .

As previously mentioned, the cloud point method was used for the determination of the thiophene solubility in the selected DESs. For this method, a certain amount of DES was placed in a $20 \mathrm{~mL}$ headspace vial and thiophene was added dropwise until turbidity was visually observed. Then, the composition of the samples was gravimetrically determined using a Mettler AX205 balance with an uncertainty in the measurement of \pm 0.2 $\times 10^{-4} \mathrm{~g}$. The temperature of the vial as controlled using a thermostatic bath with a temperature controller (IKA ETS-D5) with a precision of $\pm 0.1 \mathrm{~K}$.

\section{RESULTS AND DISCUSSION}

3.1. Binary LLE Experiments. The LLE equilibrium data of the binary systems $\{n$-hexane + DES 1$\},\{n$-hexane + DES $2\},\{n$-octane + DES 1$\}$, and $\{n$-octane + DES 2$\}$ were experimentally determined using the equilibrium cell method. The obtained values are listed in Table 5 . The binary systems \{thiophene + DES 1$\}$, \{thiophene + DES 2\} were determined by the cloud-point methods and the results are listed in Table 6.

As can be observed from Table 5 and Table 6, the solubility of thiophene in DES 1 and DES 2 is much larger than those of the aliphatic hydrocarbons. The solubility in DES 1 and DES 2

Table 5. Equilibrium Compositions (Weight Fraction) In the Binary Mixtures of $\{\text { Aliphatic (1) }+ \text { DES } 1 \text { (2) }\}^{a}$

$\begin{array}{cc}\text { system } & w_{1} \text { (bottom phase) } \\ \{n \text {-hexane }(1)+\text { DES 1 (2) } & 0.103 \pm 0.003 \\ \{n \text {-hexane }(1)+\text { DES 2 (2) } & 0.049 \pm 0.001 \\ \{n \text {-octane }(1)+\text { DES 1 (2) } & 0.073 \pm 0.001 \\ \{n \text {-octane }(1)+\text { DES 2 }(2)\} & 0.039 \pm 0.005\end{array}$

${ }^{a}$ Standard uncertainty in temperature $u(T / K)=0.1$. 
Table 6. Solubility of Thiophene in DES 1 and DES 2 (Weight Fraction) As Determined by the Cloud Point Method at $T / K=298.2$ and Atmospheric Pressure

\begin{tabular}{cl}
\multicolumn{1}{c}{ system } & \multicolumn{1}{c}{$w_{1}$} \\
\{thiophene $(1)+$ DES 1 (2) & fully soluble \\
thiophene $(1)+$ DES 2 (2) & 0.821 \\
\hline
\end{tabular}

decreased in the following order: thiophene $\gg n$-hexane $>n$ octane. This difference can be presumably related to the electrostatic interactions between the $\pi$-electrons present in the thiophene and the cations of the DES. Moreover, the interactions between the sulfur; due to its electron density and the components of the DES might also play a role. ${ }^{31}$ The thiophene was found to be fully soluble in DES 1 (containing ethylene glycol as a HBD), while only partially soluble in DES 2 (containing glycerol as a HBD). The steric hindrance around $\mathrm{C}-\mathrm{O}$ in glycerol is greater than that of ethylene glycol, which leads to the lower solubility of the thiophene in DES $2^{32}$ (see Table 6). It worth mentioning that the solubility of thiophene in DES 1 and DES 2 is significantly greater than its solubility in pure ethylene glycol and glycerol presented in the Supporting Information (Table S.1). Therefore, the addition of the salt "tetrahexylammonium bromide" to form DES 1 and DES 2 has remarkably increased the solubility of thiophene. This proves the aforementioned speculation that the thiophene $\pi$-electrons interact with the DES cations. Another factor is that the anion $\left[\mathrm{Br}^{-}\right]$of the salt could also play a role of disrupting the

Table 7. Experimental LLE Data in Weight Fractions for the Ternary Systems $\{n$-Hexane + Thiophene + DES 1$\},\{n$-Hexane + Thiophene + DES 2\}, $\{n$-Octane + Thiophene + DES 1 $\}$, and $\{n$-Octane + Thiophene + DES 1$\}$ at $T / K=298.2$ and Atmospheric Pressure. $\beta$ and $S$ Are the Calculated Distribution Coefficient and Selectivity Values ${ }^{a}$

\begin{tabular}{|c|c|c|c|c|c|}
\hline \multicolumn{2}{|c|}{ Aliphatic phase } & \multicolumn{2}{|c|}{ DES phase } & \multirow[b]{2}{*}{$\beta$} & \multirow[b]{2}{*}{$S$} \\
\hline$w_{1}$ & $w_{2}$ & $w_{1}$ & $w_{2}$ & & \\
\hline \multicolumn{6}{|c|}{$n$-Hexane $(1)+$ Thiophene (2) + DES $1(3)$} \\
\hline $0.947 \pm 0.001$ & $0.053 \pm 0.001$ & $0.110 \pm 0.002$ & $0.049 \pm 0.001$ & $0.935 \pm 0.016$ & $8.05 \pm 0.19$ \\
\hline $0.896 \pm 0.002$ & $0.104 \pm 0.002$ & $0.114 \pm 0.001$ & $0.094 \pm 0.001$ & $0.902 \pm 0.017$ & $7.06 \pm 0.15$ \\
\hline $0.845 \pm 0.003$ & $0.155 \pm 0.003$ & $0.127 \pm 0.003$ & $0.138 \pm 0.002$ & $0.888 \pm 0.018$ & $5.90 \pm 0.19$ \\
\hline $0.795 \pm 0.004$ & $0.205 \pm 0.004$ & $0.140 \pm 0.005$ & $0.178 \pm 0.002$ & $0.868 \pm 0.021$ & $4.92 \pm 0.22$ \\
\hline $0.746 \pm 0.004$ & $0.254 \pm 0.004$ & $0.156 \pm 0.005$ & $0.220 \pm 0.003$ & $0.869 \pm 0.019$ & $4.15 \pm 0.15$ \\
\hline $0.697 \pm 0.003$ & $0.303 \pm 0.003$ & $0.168 \pm 0.004$ & $0.259 \pm 0.004$ & $0.854 \pm 0.016$ & $3.54 \pm 0.11$ \\
\hline $0.602 \pm 0.007$ & $0.398 \pm 0.007$ & $0.194 \pm 0.006$ & $0.323 \pm 0.004$ & $0.810 \pm 0.018$ & $2.52 \pm 0.10$ \\
\hline $0.489 \pm 0.003$ & $0.511 \pm 0.003$ & $0.231 \pm 0.003$ & $0.417 \pm 0.003$ & $0.816 \pm 0.007$ & $1.73 \pm 0.03$ \\
\hline \multicolumn{6}{|c|}{$n$-Hexane $(1)+$ Thiophene $(2)+$ DES $2(3)$} \\
\hline $0.949 \pm 0.001$ & $0.051 \pm 0.001$ & $0.058 \pm 0.001$ & $0.040 \pm 0.001$ & $0.789 \pm 0.018$ & $12.99 \pm 0.34$ \\
\hline $0.896 \pm 0.002$ & $0.104 \pm 0.002$ & $0.060 \pm 0.001$ & $0.078 \pm 0.001$ & $0.750 \pm 0.016$ & $11.29 \pm 0.28$ \\
\hline $0.840 \pm 0.002$ & $0.160 \pm 0.002$ & $0.066 \pm 0.001$ & $0.115 \pm 0.001$ & $0.717 \pm 0.009$ & $9.09 \pm 0.13$ \\
\hline $0.781 \pm 0.001$ & $0.219 \pm 0.001$ & $0.075 \pm 0.003$ & $0.154 \pm 0.003$ & $0.705 \pm 0.016$ & $7.38 \pm 0.34$ \\
\hline $0.730 \pm 0.004$ & $0.270 \pm 0.004$ & $0.079 \pm 0.001$ & $0.187 \pm 0.001$ & $0.691 \pm 0.011$ & $6.37 \pm 0.15$ \\
\hline $0.672 \pm 0.006$ & $0.328 \pm 0.006$ & $0.084 \pm 0.001$ & $0.217 \pm 0.001$ & $0.662 \pm 0.013$ & $5.31 \pm 0.13$ \\
\hline $0.582 \pm 0.004$ & $0.418 \pm 0.004$ & $0.099 \pm 0.002$ & $0.277 \pm 0.001$ & $0.662 \pm 0.007$ & $3.89 \pm 0.09$ \\
\hline $0.477 \pm 0.004$ & $0.523 \pm 0.004$ & $0.112 \pm 0.001$ & $0.348 \pm 0.001$ & $0.665 \pm 0.005$ & $2.82 \pm 0.04$ \\
\hline $0.367 \pm 0.003$ & $0.633 \pm 0.003$ & $0.128 \pm 0.002$ & $0.438 \pm 0.003$ & $0.692 \pm 0.006$ & $1.99 \pm 0.04$ \\
\hline $0.250 \pm 0.004$ & $0.750 \pm 0.004$ & $0.133 \pm 0.002$ & $0.556 \pm 0.002$ & $0.742 \pm 0.005$ & $1.40 \pm 0.02$ \\
\hline \multicolumn{6}{|c|}{$n$-Octane $(1)+$ Thiophene $(2)+$ DES $1(3)$} \\
\hline $0.948 \pm 0.002$ & $0.052 \pm 0.002$ & $0.079 \pm 0.002$ & $0.051 \pm 0.001$ & $0.981 \pm 0.033$ & $11.71 \pm 0.47$ \\
\hline $0.898 \pm 0.002$ & $0.102 \pm 0.002$ & $0.087 \pm 0.001$ & $0.098 \pm 0.001$ & $0.961 \pm 0.016$ & $9.95 \pm 0.18$ \\
\hline $0.851 \pm 0.002$ & $0.149 \pm 0.002$ & $0.094 \pm 0.003$ & $0.145 \pm 0.003$ & $0.976 \pm 0.024$ & $8.87 \pm 0.34$ \\
\hline $0.802 \pm 0.002$ & $0.198 \pm 0.002$ & $0.105 \pm 0.001$ & $0.186 \pm 0.001$ & $0.941 \pm 0.010$ & $7.18 \pm 0.11$ \\
\hline $0.747 \pm 0.009$ & $0.253 \pm 0.009$ & $0.114 \pm 0.002$ & $0.221 \pm 0.002$ & $0.873 \pm 0.032$ & $5.73 \pm 0.24$ \\
\hline $0.693 \pm 0.004$ & $0.307 \pm 0.004$ & $0.128 \pm 0.001$ & $0.267 \pm 0.001$ & $0.869 \pm 0.011$ & $4.72 \pm 0.07$ \\
\hline $0.593 \pm 0.008$ & $0.407 \pm 0.008$ & $0.152 \pm 0.002$ & $0.335 \pm 0.002$ & $0.822 \pm 0.017$ & $3.20 \pm 0.09$ \\
\hline $0.486 \pm 0.006$ & $0.514 \pm 0.006$ & $0.186 \pm 0.002$ & $0.409 \pm 0.003$ & $0.797 \pm 0.011$ & $2.08 \pm 0.04$ \\
\hline \multicolumn{6}{|c|}{$n$-Octane $(1)+$ Thiophene $(2)+$ DES $2(3)$} \\
\hline $0.946 \pm 0.001$ & $0.054 \pm 0.001$ & $0.043 \pm 0.006$ & $0.043 \pm 0.001$ & $0.794 \pm 0.022$ & $17.30 \pm 2.15$ \\
\hline $0.891 \pm 0.001$ & $0.109 \pm 0.001$ & $0.050 \pm 0.004$ & $0.081 \pm 0.002$ & $0.747 \pm 0.020$ & $13.35 \pm 1.04$ \\
\hline $0.839 \pm 0.002$ & $0.161 \pm 0.002$ & $0.052 \pm 0.006$ & $0.121 \pm 0.004$ & $0.752 \pm 0.027$ & $12.08 \pm 1.36$ \\
\hline $0.780 \pm 0.001$ & $0.220 \pm 0.001$ & $0.061 \pm 0.005$ & $0.163 \pm 0.011$ & $0.741 \pm 0.048$ & $9.50 \pm 0.98$ \\
\hline $0.727 \pm 0.003$ & $0.273 \pm 0.003$ & $0.061 \pm 0.001$ & $0.188 \pm 0.001$ & $0.688 \pm 0.007$ & $8.21 \pm 0.20$ \\
\hline $0.671 \pm 0.002$ & $0.329 \pm 0.002$ & $0.065 \pm 0.005$ & $0.225 \pm 0.001$ & $0.684 \pm 0.006$ & $7.04 \pm 0.54$ \\
\hline $0.582 \pm 0.002$ & $0.418 \pm 0.002$ & $0.075 \pm 0.005$ & $0.281 \pm 0.001$ & $0.673 \pm 0.004$ & $5.21 \pm 0.36$ \\
\hline $0.473 \pm 0.002$ & $0.527 \pm 0.002$ & $0.085 \pm 0.005$ & $0.350 \pm 0.004$ & $0.665 \pm 0.008$ & $3.69 \pm 0.21$ \\
\hline $0.363 \pm 0.001$ & $0.637 \pm 0.001$ & $0.099 \pm 0.004$ & $0.443 \pm 0.005$ & $0.696 \pm 0.008$ & $2.55 \pm 0.10$ \\
\hline $0.251 \pm 0.001$ & $0.749 \pm 0.001$ & $0.112 \pm 0.002$ & $0.557 \pm 0.006$ & $0.744 \pm 0.008$ & $1.66 \pm 0.04$ \\
\hline
\end{tabular}

${ }^{a}$ Standard uncertainty in temperature $u(T / K)=0.1$. 

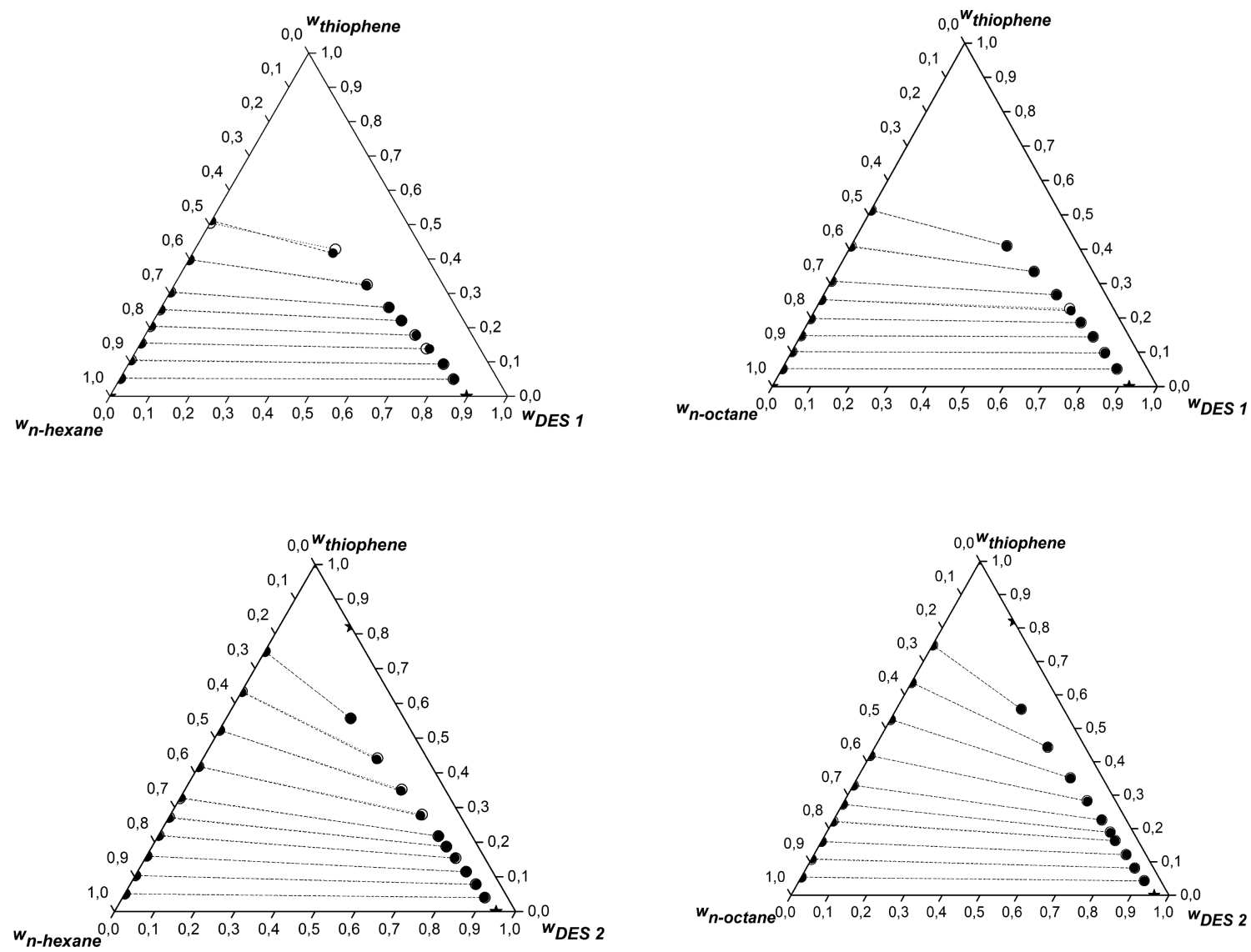

Figure 1. Experimental tie lines $(\bullet$, dashed line) in weight fractions for the ternary systems $\{n$-hexane + thiophene $+D E S 1\},\{n$-hexane + thiophene + DES 2$\},\{n$-octane + thiophene + DES 1$\}$, and $\{n$-octane + thiophene + DES 2$\}$ at $T / K=298.2$ and atmospheric pressure; experimental binary solubilites $(\star)$ for the systems $\{n$-hexane or $n$-octane or thiophene + DES 1 and DES 2$\}$; calculated equilibrium points $(O$, dotted line) using NRTL.

hydrogen-bond network for ethylene glycol and glycerol. This disruption could also allow for improved interactions and additional void space to accommodate thiophene.

From Table 5, it is observed that the solubility of aliphatic hydrocarbon ( $n$-hexane and/or $n$-octane) in the DESs is relatively small due to their low polarity, which limits the solubility in the polar DESs. The solubility of $n$-hexane in DES 1 and DES 2 is slightly higher than $n$-octane. The lower solubility of $n$-octane in the DES could be due to its lower chemical potential versus $n$-hexane.

The large differences in the solubilities of the \{aliphatic + DES $\}$ and \{thiophene + DES \} binary systems, implies that the selected DESs are potential extractants for the separation of aliphatic/thiophene mixtures.

3.2. Ternary LLE Experiments. The LLE data of the ternary systems $\{n$-hexane + thiophene + DES 1$\},\{n$-hexane + thiophene + DES 2$\},\{n$-octane + thiophene + DES 1$\}$, and $\{n$ octane + thiophene + DES 2$\}$ were experimentally determined at $T / \mathrm{K}=298.2$ and atmospheric pressure. The obtained results are shown in Table 7 and graphically depicted in Figure 1 by means of triangular diagrams.

From Figure 1, it can be observed that the miscibility region slightly decreases with the increase of the aliphatic carbon number. This is reasonable based on the binary solubilites, which follow the order: thiophene $\gg n$-hexane $>n$-octane for both DESs (see section 3.1). According to the Sørensen et al. classification, ${ }^{33}$ the two ternary systems \{n-hexane $/ n$-octane + thiophene + DES 1 \} showed a type I ternary behavior, in which two of the pairs of compounds exhibit complete miscibility ( $\{$ aliphatic + thiophene $\}$ and $\{$ thiophene + DES 1$\})$. While, the two ternary systems $\{n$-hexane $/ n$-octane + thiophene + DES 2$\}$ showed a type II ternary behavior. This is one completely miscible pair \{aliphatic + thiophene $\}$ and two partially miscible ones $\{$ aliphatic + DES $\}$ and $\{$ thiophene + DES $\}$ with only one immiscibility region.

The aliphatic phase was found to be DES-free, and this was verified via ${ }^{1} \mathrm{H}$ NMR. The obtained spectra are presented in the Supporting Information (Figures S.3 and S.4). As it can be seen from the spectra, within the detection limits of the equipment $(<0.1$ wt $\%)$, only $n$-hexane or $n$-octane and thiophene were detected in the aliphatic-rich phase samples. This behavior was also observed in systems of \{aliphatic + thiophene + ILs\}. ${ }^{15,17-19,34}$ The absence of the DES can prevent solvent losses during extraction, and this is an added value from an economical point of view.

The performance of the studied DESs on the extraction of thiophene can be evaluated using the distribution coefficient and the selectivity.

The solute distribution coefficient $(\beta)$ measures the concentration of the solute in the extract phase (DES-rich phase) with respect to its concentration in the raffinate phase (aliphatic-rich phase). It can be calculated from the experimental data as follows: ${ }^{35}$

$$
\beta_{2}=\frac{w_{2, \mathrm{E}}}{w_{2, \mathrm{R}}}
$$


where $w_{2, \mathrm{E}}$ is the weight fraction of thiophene in the DES-rich phase and $w_{2, \mathrm{R}}$ is the weight fraction of thiophene in the aliphatic-rich phase. The values of the distribution coefficient are presented in Table 7 and graphically shown in Figure 2. The

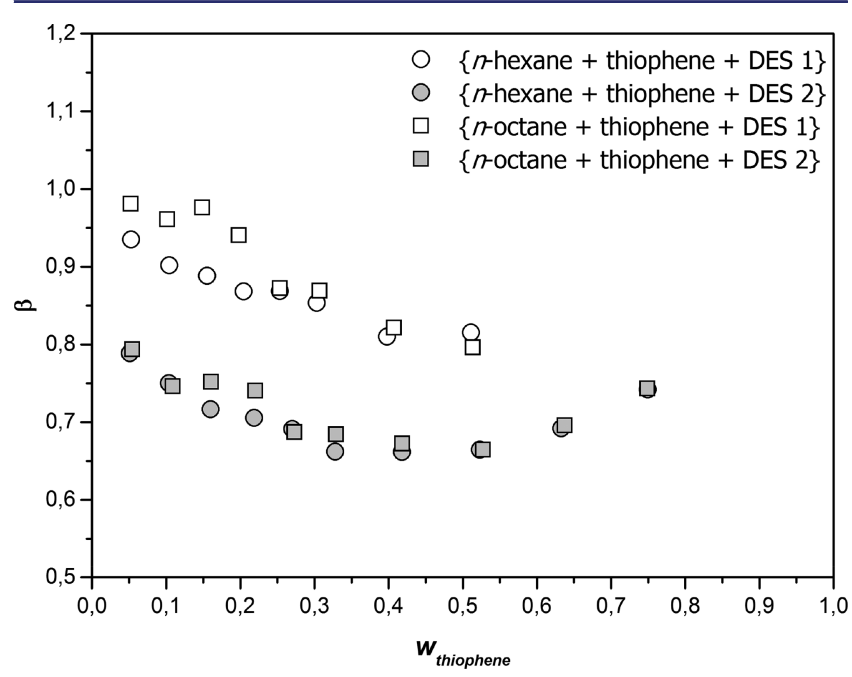

Figure 2. Solute distribution coefficient as a function of the weight fraction of thiophene in the aliphatic-rich phase.

higher the $\beta$, the better the quality of the raffinate and consequently more thiophene is extracted. This implies that less solvent is needed to achieve the desired efficiency.

For all the measured systems, the distribution coefficient was found to be less than unity. As shown in Figure 2, for the systems $\{n$-hexane + thiophene + DES 1$\}$ and $\{n$-octane + thiophene + DES 1$\}$ the distribution coefficient decreases with an increase in the thiophene concentration (at least up to a thiophene weight fraction equal to 0.5 ). While for the system $\{n$-hexane + thiophene + DES 2$\}$ the distribution coefficient decreases with an increase in the thiophene concentration, reaching a minimum value of $\beta=0.66$ at the concentration range of $(0.3-0.5)$, followed by an increase in the distribution coefficient with a further increase in the thiophene concentration. The system $\{n$-octane + thiophene + DES 2$\}$ shows a similar behavior with a single minimum of $\beta=0.66$ corresponding to $\left(w_{2}=0.5\right)$. This behavior of the distribution coefficient has also been observed for DES 2 (tetrahexylammonium bromide/glycerol (1:2)) in the separation of aromatic compounds from aliphatic hydrocarbons using the same DES. ${ }^{30}$ In general, the distribution coefficient for DES 1 is found be greater than for DES 2. This behavior could be expected based on the full solubility of the thiophene in DES 1 .

The selectivity of the thiophene over the aliphatic compound can be measured by the separation factor, which is more often simply called selectivity $(S)$, and is defined as ${ }^{35}$

$$
S=\frac{\beta_{2}}{\beta_{1}}
$$

where $\beta_{1}$ and $\beta_{2}$ refer to the distribution coefficients of the aliphatic compound and thiophene, respectively. The calculated selectivity values are presented in Table 7 , and depicted in Figure 3. As shown in Figure 3, the selectivity decreases with an increase in the thiophene concentration. In the four studied systems the selectivity was found to be greater than unity. This implies that the extraction of thiophene using DESs is feasible.

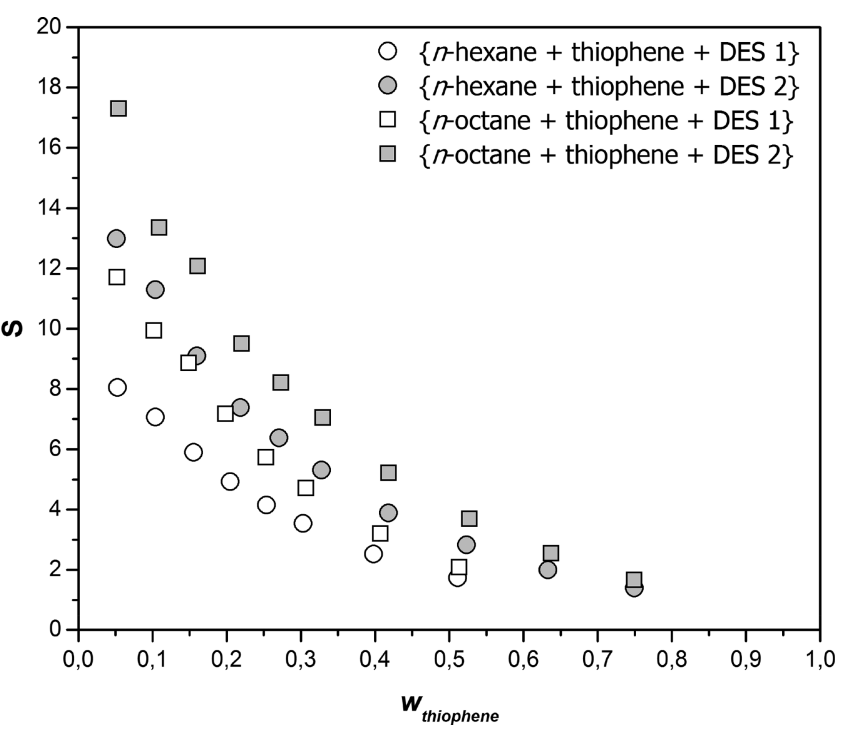

Figure 3. Selectivity as a function of the weight fraction of thiophene in the aliphatic-rich phase.

It can be observed that DES 2 has a greater selectivity for thiophene over $n$-hexane and $n$-octane compared to DES 1 . This can be explained based on the binary solubility differences of the systems \{aliphatic + DES 1 \} and \{aliphatic + DES 2\}. DES 1 showed higher solubilites of the aliphatic compounds, thus lower selectivites. Higher selectivities are obtained for the \{octane + thiophene + DES $\}$ in comparison to the hexane + thiophene $+\mathrm{DES}\}$, this can also be explained on the basis of the binary solubilities presented in the previous section.

On the basis of the obtained LLE results, it can be concluded that DES 1 and DES 2 are potential candidates for the desulfurization of fuels. The use of DES 1 is preferable in comparison with DES 2. The higher distribution coefficients indicate that a lower solvent-to-feed ratio is needed, therefore its use is more economically feasible. Moreover, at the studied extraction conditions $(T / K=298.2$ and atmospheric pressure) DES 1 is about $78 \%$ less viscous than DES $2,{ }^{30}$ which makes it easier to handle and more economical in terms of process design.

3.3. NTRL Regression. In this section the experimentally obtained LLE data were correlated using the nonrandom two liquid (NRTL) model. The NRTL model is an activity coefficient $\left(\gamma_{i}\right)$ model based on the concept of local composition. It has been widely used for partially miscible systems. It is defined as ${ }^{36}$

$$
\ln \gamma_{i}=\frac{\sum_{j} x_{j} \tau_{j i} G_{j i}}{\sum_{k} x_{k} G_{k i}}+\sum_{j} \frac{x_{j} G_{i j}}{\sum_{k} x_{k} G_{k j}}\left(\tau_{i j}-\frac{\sum_{m} x_{m} \tau_{m j} G_{m j}}{\sum_{k} x_{k} G_{k j}}\right)
$$

where

$$
\begin{gathered}
G_{i j}=\mathrm{e}^{\left(-\alpha_{i j} \tau_{i j}\right)} \\
\tau_{i j}=a_{i j}+\frac{b_{i j}}{T} \\
\alpha_{i j}=c_{i j}=c_{j i}
\end{gathered}
$$

and $x_{i}$ is the mole fraction of component $i$; however, in this work the weight fraction has been used because of the large molecular mass of the DESs. This is a common strategy for 
Table 8. Binary Interaction Parameters for the NRTL Model and the Root Mean Square Deviation (RMSD \%) from the Experimentally Determined Ternary LLE

\begin{tabular}{|c|c|c|c|c|c|c|c|}
\hline$i$ & j & $a_{i j}\left(\mathrm{~J} \cdot \mathrm{K}^{-1} \cdot \mathrm{mol}^{-1}\right)$ & $a_{j i}\left(\mathrm{~J} \cdot \mathrm{K}^{-1} \cdot \mathrm{mol}^{-1}\right)$ & $b_{i j}\left(\mathrm{~J} \mathrm{~mol}^{-1}\right)$ & $b_{j i}\left(\mathrm{~J} \mathrm{~mol}^{-1}\right)$ & $c_{i j}$ & RMSD (\%) \\
\hline$n$-hexane & thiophene & -6.9 & 25.0 & -5672.4 & 21400.7 & 0.3 & 0.33 \\
\hline$n$-hexane & DES 1 & 5.0 & -1.3 & 2304.7 & 1834.5 & 0.3 & \\
\hline thiophene & DES 1 & 50.4 & 4.1 & 15098.7 & 1505.1 & 0.3 & \\
\hline$n$-hexane & thiophene & 5.7 & 25.4 & -2017.4 & -6880.4 & 0.3 & 0.15 \\
\hline$n$-hexane & DES 2 & 10.8 & 8.2 & -3023.6 & -1704.8 & 0.3 & \\
\hline thiophene & DES 2 & 64.8 & -14.2 & -14772.6 & 4116.0 & 0.3 & \\
\hline$n$-octane & thiophene & -12.1 & -54.2 & 3594.9 & 16590.8 & 0.3 & 0.13 \\
\hline DES 1 & $n$-octane & -32.6 & -7.5 & 10287.2 & 2793.5 & 0.3 & \\
\hline DES 1 & thiophene & 4.4 & 9.9 & -1262.5 & 453.8 & 0.3 & \\
\hline$n$-octane & thiophene & 6.5 & -12.9 & -2389.7 & 4447.0 & 0.3 & 0.07 \\
\hline DES 2 & $n$-octane & -115.4 & -13.9 & 35116.9 & 4603.1 & 0.3 & \\
\hline DES 2 & thiophene & -63.9 & -6.7 & 18573.1 & 4049.5 & 0.3 & \\
\hline
\end{tabular}

polymeric systems with large molecular masses. ${ }^{37}$ The parameter $c_{i j}$ is a symmetrical parameter that is equal to the nonrandomness parameter $\alpha_{i j}$ and was fixed at a value of 0.3 , which is the recommended value for nonpolar substances and nonpolar with polar nonassociated liquids. The root-meansquare deviation (RMSD \%) from the experimental data was calculated as

$$
\operatorname{RMSD}(\%)=\sqrt{\frac{\left(w_{\text {hex }}^{\text {exp }}-w_{\text {hex }}^{\text {cal }}\right)^{2}+\left(w_{\text {thio }}^{\text {exp }}-w_{\text {thio }}^{\text {cal }}\right)^{2}+\left(w_{\mathrm{DES}}^{\exp }-w_{\mathrm{DES}}^{\text {cal }}\right)^{2}}{2 M N}} \cdot 100
$$

where $M$ is the number of tie-lines and $N$ is the number of compounds.

The LLE data were regressed using Aspen Plus. The estimated values of the binary parameters and the deviation for the experimental data are presented in Table 8 .

3.4. DES Regeneration. In terms of designing an economical desulfurization process, the regeneration of the DES is an important step. The regeneration of DES 1 was performed under vacuum using a rotary evaporator at $T / \mathrm{K}=$ 303 and a pressure of $<100$ mbar. A sample of a DES-rich phase for the system $\{n$-hexane $(1)+$ thiophene $(2)+\operatorname{DES} 1$ (3) with the composition $\left(w_{1}=0.110, w_{2}=0.049\right.$, and $\left.w_{3}=0.840\right)$ was placed in the rotatory evaporator for $12 \mathrm{~h}$. Thereafter, the regenerated DES was analyzed via ${ }^{1} \mathrm{H}$ NMR. From the obtained NMR spectra (shown in the Supporting Information, Figure S.5), the fresh DES and the regenerated DES structures are identical, and no traces of $n$-hexane and thiophene were detected.

3.5. Literature Comparison. The performance of the DESs has been compared to the performance of those systems using ILs as extracting agents. The comparison factors were the distribution coefficient and the selectivity, calculated at $T / \mathrm{K}=$ 298.2 and atmospheric pressure. It should be mentioned that the comparisons were done on a mass basis due to the differences in the molar masses of the solvents. The mass basis comparisons are more realistic and practical for large scale/ industrial solvent selection. The distribution coefficients for the systems $\{n$-hexane + thiophene $+\mathrm{DES} / \mathrm{IL}\}$ and $\{n$-octane + thiophene $+\mathrm{DES} / \mathrm{IL}\}$ can be found in Figure 4 and Figure 6, respectively. The selectivities for the systems $\{n$-hexane + thiophene $+\mathrm{DES} / \mathrm{IL}\}$ and $\{n$-octane + thiophene $+\mathrm{DES} / \mathrm{IL}\}$ can be found in Figure 5 and Figure 7, respectively. From Figure 4 it can be observed that the distribution coefficients of the systems $\{n$-hexane + thiophene $+\mathrm{DES} / \mathrm{IL}\}$ are similar, and in some cases the DES shows higher distribution coefficients

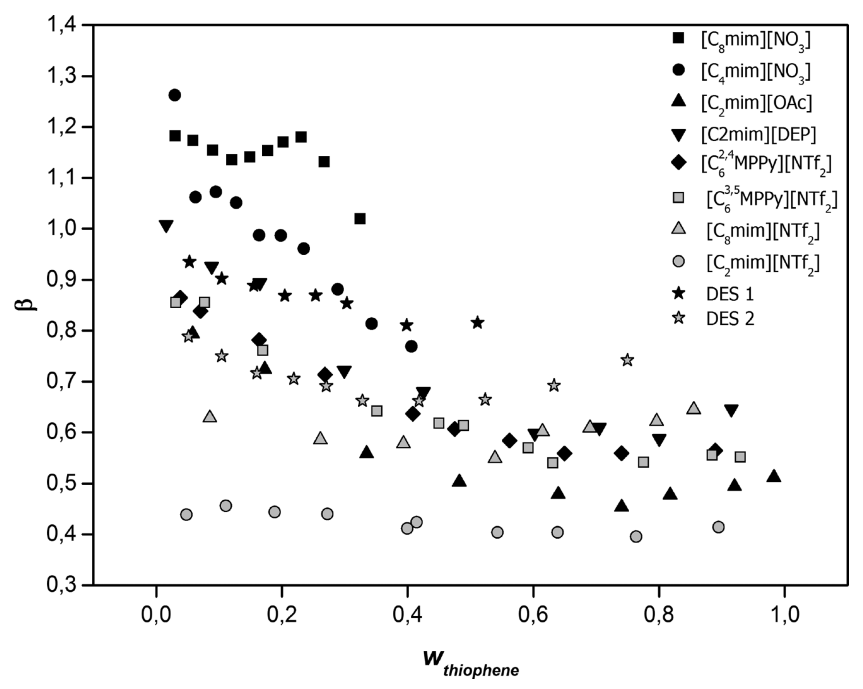

Figure 4. Solute distribution coefficient as a function of the weight fraction of thiophene in the aliphatic-rich phase for the system $\{n$ hexane + thiophene + IL or DES $\}^{14-19}$

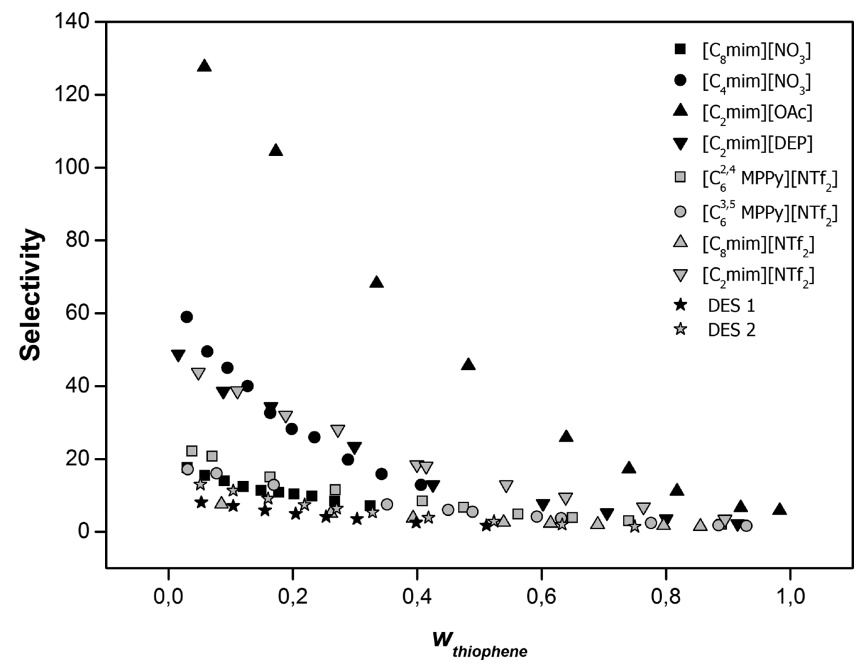

Figure 5. Selectivity as a function of the weight fraction of thiophene in the aliphatic-rich phase for the system $\{n$-hexane + thiophene + IL or DES $\}^{14-19}$

than the ILs, except for $\left[\mathrm{C}_{8} \mathrm{mim}\right]\left[\mathrm{NO}_{3}\right]$ and $\left[\mathrm{C}_{4} \mathrm{mim}\right]\left[\mathrm{NO}_{3}\right]$. As shown in Figure 5, the selectivities of the DESs were found to be somewhat lower than those of the studied ILs. 


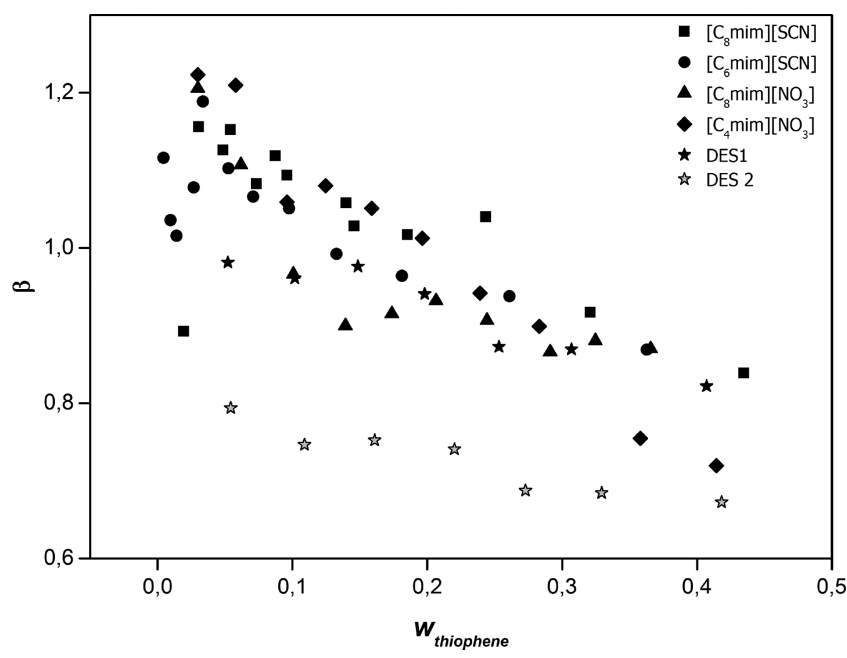

Figure 6. Solute distribution coefficient as a function of the weight fraction of thiophene in the aliphatic-rich phase for the system $\{n$ octane + thiophene $+\mathrm{IL}$ or DES $\}^{16,34}$

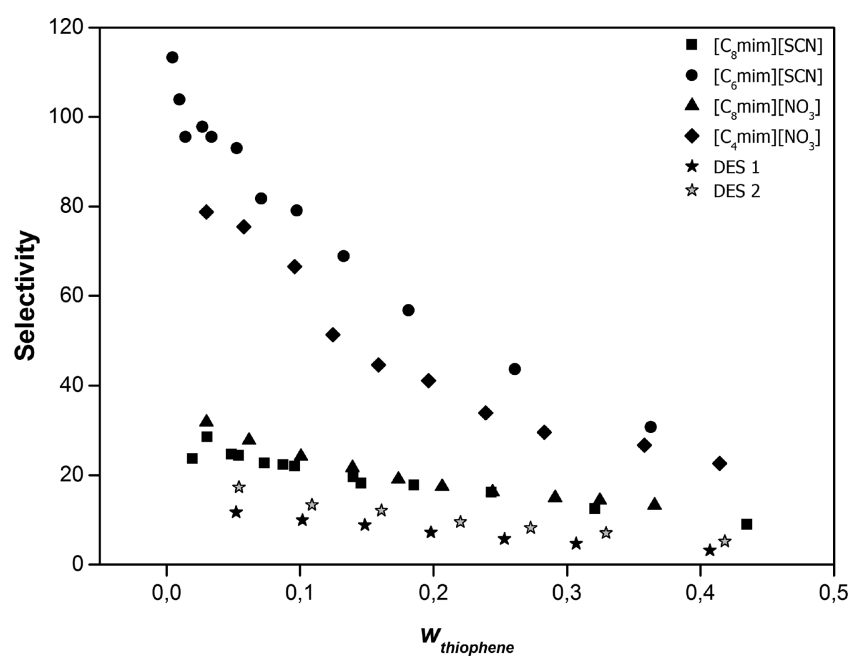

Figure 7. Selectivity as a function of the weight fraction of thiophene in the aliphatic-rich phase for the system n-octane + thiophene + IL or DES $\}^{16,34}$

For the systems $\{n$-octane + thiophene + DES $/ \mathrm{IL}\}$, both the distribution coefficients and the selectivites of the DESs were comparable, but somewhat lower than those of all the studied ILs (see Figure 6 and Figure 7). The distribution coefficient is an important factor for the design of an economical process. The higher the distribution factor, the smaller the amount of the solvent needed. This is beneficial because it reduces the operational cost for solvent recovery. DESs are easier to prepare compared to ILs (no synthesis required, just mixing is enough). As mentioned previously, DESs can be prepared from cheap starting materials (e.g., tetrahexylammonium bromide, ethylene glycol, and glycerol). Further studies should contemplate if the lower price of the solvent compensates the slightly higher amount of solvent needed.

\section{CONCLUSIONS}

In this work, two deep eutectic solvents (DESs) were evaluated for their extraction properties of thiophene from two aliphatic hydrocarbons via liquid-liquid extraction. The aliphatic hydrocarbons were $n$-hexane and $n$-octane. The selected
DESs were (i) tetrahexylammonium bromide/ethylene glycol with molar ratio $=1: 2($ DES 1$)$, and (ii) tetrahexylammonium bromide/glycerol with molar ratio $=1: 2($ DES 2$)$. The first step was to determine the binary solubility of $\{$ thiophene $+\mathrm{DES}\}$ and $\{$ aliphatic $+\mathrm{DES}\}$ at $T / \mathrm{K}=298.2$ and atmospheric pressure. Then, the liquid-liquid equilibrium (LLE) data of the ternary systems $\{n$-hexane + thiophene + DES 1$\},\{n$-hexane + thiophene + DES 2$\},\{n$-octane + thiophene + DES 1$\}$, and $\{n$ octane + thiophene + DES 2$\}$ were determined at $T / K=298.2$ and atmospheric pressure. Also, the solute distribution ratios and the selectivities were calculated from the experimental LLE data. It was found that the distribution coefficients obtained for the DES 1 are always higher than those of DES 2, while the opposite trend was found for the selectivity. Moreover, it was found that, for the same DES, higher distribution coefficients and lower selectivities were obtained for the \{hexane + thiophene + DES $\}$ system than for the \{octane + thiophene + DES $\}$ system. NRTL regression has been carried out, and the experimental data could be satisfactorily correlated to the model. Regeneration of the DESs has been successfully achieved by means of vacuum evaporation. On the basis of the obtained distribution coefficients and selectivities, DESs were found to be competitors for the desulfurization of fuels to ILs with almost similar performance but lower price.

\section{ASSOCIATED CONTENT}

\section{Supporting Information}

The Supporting Information is available free of charge on the ACS Publications website at DOI: 10.1021/acs.jced.7b00168.

${ }^{1} \mathrm{H}$ NMR spectra of DES 1 and DES 2, the absence of DES in the system $\{n$-hexane + thiophene + DES 1$\}$, the absence of DES in the system $\{n$-octane + thiophene + DES 1$\}$, and the DES regeneration (PDF)

\section{AUTHOR INFORMATION}

\section{Corresponding Author}

*E-mail: mkroon@pi.ac.ae. Tel.: +971-26075317.

ORCID

J. Ilja Siepmann: 0000-0003-2534-4507

Maaike C. Kroon: 0000-0002-5985-986X

\section{Funding}

Petroleum Institute Research Center (PIRC) Grant "Advanced PVT-Properties and Molecular Modeling of Complex Fluids in Support of Safe and Green Hydrocarbon Production" (Project Code LTR14009).

\section{Notes}

The authors declare no competing financial interest.

\section{ACKNOWLEDGMENTS}

We would like to gratefully acknowledge the financial support from the Petroleum Institute Research Center (PIRC) through a grant entitled "Advanced PVT-Properties and Molecular Modeling of Complex Fluids in Support of Safe and Green Hydrocarbon Production” (Project Code LTR14009).

\section{REFERENCES}

(1) Portney, P. R. Economics and the Clean Air Act. J. Econ. Perspect. Fall 1990, 4, 173-181.

(2) Rodriguez, J. A.; Hrbek, J. Interaction of Sulfur with Well-Defined Metal and Oxide Surfaces: Unraveling the Mysteries behind Catalyst Poisoning and Desulfurization. Acc. Chem. Res. 1999, 32, 719-728. 
(3) Kelemen, S. R.; George, G. N.; Gorbaty, M. L. Direct Determination and Quantification of of Sulphur Forms in Heavy Petroleum and Coals, 1. Fuel 1990, 69, 939-944.

(4) Brunet, S.; Mey, D.; Perot, G.; Bouchy, C.; Diehl, F. On the Hydrodesulfurization of FCC Gasoline: A Review. Appl. Catal., A 2005, 278, 143-172.

(5) Shafi, R.; Hutchings, G. J. Hydrodesulfurization of Hindered Dibenzothiophenes: An Overview. Catal. Today 2000, 59, 423-442.

(6) Debajyoti, B. Design Parameters for a Hydro Desulfurization (HDS) Unit for Petroleum Naphtha at 3500 Barrels per Day. World Sci. News 2015, 3, 99-111.

(7) Gatan, R.; Barger, P.; Gembicki, V.; Cavanna, A.; Molinari, D. Oxidative Desulfurization: A New Technology for ULSD. ACS Div. Fuel Chem. Prepr. 2004, 49, 577-579.

(8) Song, C.; Ma, X. New Design Approaches to Ultra-Clean Diesel Fuels by Deep Desulfurization and Deep Dearomatization. Appl. Catal., B 2003, 41, 207-238.

(9) Muzic, M.; Sertic-Bionda, K.; Gomzi, Z.; Podolski, S.; Telen, S. Study of Diesel Fuel Desulfurization by Adsorption. Chem. Eng. Res. Des. 2010, 88, 487-495.

(10) Ali, S. H.; Hamad, D. M.; Albusairi, B. H.; Fahim, M. A. Removal of Dibenzothiophenes from Fuels by Oxy-Desulfurization. Energy Fuels 2009, 23, 5986-5994.

(11) Kianpour, E.; Azizian, S. Polyethylene Glycol as a Green Solvent for Effective Extractive Desulfurization of Liquid Fuel at Ambient Conditions. Fuel 2014, 137, 36-40.

(12) Welton, T. Ionic Liquids in Catalysis. Coord. Chem. Rev. 2004, 248, 2459-2477.

(13) Gordon, C. M. New Developments in Catalysis Using Ionic Liquids. Appl. Catal., A 2001, 222, 101-117.

(14) Alonso, L.; Arce, A.; Francisco, M.; Soto, A. Phase Behaviour of 1-Methyl-3-Octylimidazolium Bis[trifluoromethylsulfonyl]imide with Thiophene and Aliphatic Hydrocarbons: The Influence of N-Alkane Chain Length. Fluid Phase Equilib. 2008, 263, 176-181.

(15) Francisco, M.; Arce, A.; Soto, A. Ionic Liquids on Desulfurization of Fuel Oils. Fluid Phase Equilib. 2010, 294, 39-48.

(16) Mokhtarani, B.; Mansourzareh, H.; Mortaheb, H. R. Phase Behavior of Nitrate Based Ionic Liquids with Thiophene and Alkanes. Ind. Eng. Chem. Res. 2014, 53 (3), 1256-1261.

(17) Rodríguez-Cabo, B.; Soto, A.; Arce, A. Desulfurization of FuelOils with $\left[\mathrm{C}_{2} \mathrm{mim}\right]\left[\mathrm{NTf}_{2}\right]$ : A Comparative Study. J. Chem. Thermodyn. 2013, 57, 248-255.

(18) Rodríguez-Cabo, B.; Arce, A.; Soto, A. Desulfurization of Fuels by Liquid-Liquid Extraction with 1-Ethyl-3-Methylimidazolium Ionic Liquids. Fluid Phase Equilib. 2013, 356, 126-135.

(19) Rodríguez-Cabo, B.; Francisco, M.; Soto, A.; Arce, A. Hexyl Dimethylpyridinium Ionic Liquids for Desulfurization of Fuels. Effect of the Position of the Alkyl Side Chains. Fluid Phase Equilib. 2012, 314, $107-112$.

(20) Abbott, A. P.; Capper, G.; Davies, D. L.; Rasheed, R. K.; Tambyrajah, V. Novel Solvent Properties of Choline Chloride/urea Mixtures. Chem. Commun. (Cambridge, U. K.) 2003, 1, 70-71.

(21) Durand, E.; Lecomte, J.; Villeneuve, P. From Green Chemistry to Nature: The Versatile Role of Low Transition Temperature Mixtures. Biochimie 2016, 120, 119-123.

(22) Francisco, M.; Van Den Bruinhorst, A.; Kroon, M. C. LowTransition-Temperature Mixtures (LTTMs): A New Generation of Designer Solvents. Angew. Chem., Int. Ed. 2013, 52, 3074-3085.

(23) Li, J. J.; Xiao, H.; Tang, X. D.; Zhou, M. Green Carboxylic AcidBased Deep Eutectic Solvents as Solvents for Extractive Desulfurization. Energy Fuels 2016, 30, 5411-5418.

(24) Li, C.; Li, D.; Zou, S.; Li, Z.; Yin, J.; Wang, A.; Cui, Y.; Yao, Z.; Zhao, Q. Extraction Desulfurization Process of Fuels with Ammonium-Based Deep Eutectic Solvents. Green Chem. 2013, 15, 2793-2799.

(25) Gano, Z. S.; Mjalli, F. S.; Al-Wahaibi, T.; Al-Wahaibi, Y.; AlNashef, I. M. Solubility of Thiophene and Dibenzothiophene in Anhydrous $\mathrm{FeCl}_{3}$ - and $\mathrm{ZnCl}_{2}$-Based Deep Eutectic Solvents. Ind. Eng. Chem. Res. 2014, 53, 6815-6823.
(26) Gano, Z. S.; Mjalli, F. S.; Al-wahaibi, T.; Al-wahaibi, Y. The Novel Application of Hydrated Metal Halide $\left(\mathrm{SnCl}_{2} \cdot 2 \mathrm{H}_{2} \mathrm{O}\right)-$ Based Deep Eutectic Solvent for the Extractive Desulfurization of Liquid Fuels. Int. J. Chem. Eng. Appl. 2015, 6, 367-371.

(27) Wang, X.; Jiang, W.; Zhu, W.; Li, H.; Yin, S.; Chang, Y.; Li, H. RSC Advances Desulfurization Process with Novel Deep Eutectic. RSC Adv. 2016, 6, 30345-30352.

(28) Tang, X.; Zhang, Y.; Li, J.; Zhu, Y.; Qing, D.; Deng, Y. Deep Extractive Desulfurization with Arenium Ion Deep Eutectic Solvents. Ind. Eng. Chem. Res. 2015, 54, 4625-4632.

(29) Hadj-Kali, M. K.; Mulyono, S.; Hizaddin, H. F.; Wazeer, I.; ElBlidi, L.; Ali, E.; Hashim, M. A.; AlNashef, I. M. Removal of Thiophene from Mixtures with $N$-Heptane by Selective Extraction Using Deep Eutectic Solvents. Ind. Eng. Chem. Res. 2016, 55, 84158423.

(30) Rodriguez, N. R; Requejo, P. F.; Kroon, M. C. AliphaticAromatic Separation Using Deep Eutectic Solvents as Extracting Agents. Ind. Eng. Chem. Res. 2015, 54, 11404-11412.

(31) Su, B.; Zhang, S.; Zhang, Z. C. Structural Elucidation of Thiophene Interaction with Ionic Liquids by Multinuclear NMR Spectroscopy. J. Phys. Chem. B 2004, 108, 19510-19517.

(32) Nicholas, K. M. Selective Catalysis for Renewable Feedstocks and Chemicals. Top. Curr. Chem. 2014, 353, 163.

(33) Sørensen, J. M.; Magnussen, T.; Rasmussen, P.; Fredenslund, A. Liquid-Liquid Equilibrium Data: Their Retrieval, Correlation and Prediction Part I: Retrieval. Fluid Phase Equilib. 1979, 2, 297-309.

(34) Mafi, M.; Dehghani, M. R.; Mokhtarani, B. Novel Liquid-Liquid Equilibrium Data for Six Ternary Systems Containing IL, Hydrocarbon and Thiophene at $25^{\circ} \mathrm{C}$. Fluid Phase Equilib. 2016, 412, 21-28.

(35) McKetta, J. J. Encyclopedia of Chemical Processing and Design: Vol. 21-Expanders to Finned Tubes, 1st ed.; M. Dekker, 1984.

(36) Renon, H.; Prausnitz, J. M. Local Compositions in Thermodynamic Excess Functions for Liquid Mixtures. AIChE J. 1968, 14, 135-144.

(37) Sé, R. A. G.; Aznar, M. Thermodynamic Modelling of Phase Equilibrium for Water + Poly(ethylene Glycol) + Salt Aqueous TwoPhase Systems. Braz. J. Chem. Eng. 2002, 19, 255-266. 